\section{Some comments}

ON

\section{CLINICA L U N T S.}

\section{By the RT. Hon. Sir Clifford ALlbUTT, P.C., M.D., F.R.S.,}

REGIUS PROFESSOR OF PHTSIC IN THE CNIVERSITY OF CAMBRIUGE.

Is the issue of ThE LANCEr for July 2nd of this year (p. 33) Dr. C. M. Wilson, of St. Mary's Hospital, published certain reflections of weight and importance on this subject. I have been invited to make some comments on Dr. Wilson's article, and to express a further opinion upon this new system-new in England-of medical teaching and research. Dr. Wilson's article is so far-sighted and even-handed, so well balanced between the ideal and the practical, that if I may venture to comment upon it, and to underline it, I can add nothing. How then for the best is the new system to be constructed, and to be used for these ends? We all agree that, in advanced work, teaching, if it is to be effectual, must be inspired by research : and, to most researches at any rate, teaching, if not too elementary or too laborious, is one of the incitements.

Some years ago, in the pre-war period, Sir William osler wrote to ask me to take part in an endeavour to attract to English schools some of those overseas students who then were betaking themselves to Paris, Berlin, or Vienna; but hardly deigned to visit our medical schools, even on their way. With these aspirations I agreed, warmly agreed ; but argued that these visitors would come here when there was something definite to come for, and not till then In those continental capitals, as also in the New World, Medicine was taken seriously both as science and art; as seriously, let us say, as astronomy, engineering, chemistry, agriculture, and so forth. In these and other vocations, to teaching and research highly qualified men were giving their lives. In like manner, in the foreign cities, scientific medicine was in the hands, and under the influence, of a professoriate. Yet the visitor to a great London hospital school would then have found some admirable elementary teaching for junior classes it is true; but that for the eminent men of the staffs, men whose names were household words, the hospital visit was but a part, indeed a secondary part, of their calling. As things were, the main time and available energy of these masters of their craft were spent, and necessarily spent, not in the medical school but in Harley-street. Their hospital teaching was but a scattering of crumbs from their tables. In a short hour or two the visitor would pick up some impressive and sagacious remarks; aphorisms worthy of Hippocrates; thoughts distilled out of a large empirical experience and great personal qualities; but to leisurely and systematic clinical research, to patient devotion in clinical investigation, there was hardly a pretence. Nor was any one member of a hospital staff made personally responsible for the coördination of the clinical studies. Osler's brief reply was characteristic of him: "I am showing your letter to X., Y., and Z. ; it will do them good." I need not occupy space in saying how, under one influence and another, a revolution is now coming about in certain large hospitals; a professoriate has been founded in their schools, and systematic progress is being made.

\section{Practical $v$. Theoriticat.}

There is an old and perhaps perennial schism between the " practical man" and the "man of theory" ; indeed, the word "theory" has become almost a term of abuse. Each has some right on his side, and the "practical man" is well aware of the right on his own. But in our time the development of the physical sciences has become an essential condition of congregation in large cities, as essential 5123 as was magic in the welding of primitive folk; and as under this urgency the strides they have made have been enormous, the contrast has become more and more vivid : the theoretical man is regarded as a child in affairs, the practical man as a "muddler through." 'Thus in our profession the practical, that is the clinical, man declares that he has little use for the laboratory, while the scientific physician is apt to regard the clinician as a mere empiric. Yet, if there are truths and values on both sides, we must try so to blend these opposites that each may enlighten and reinforce the other.

For it is true that if the two methods are not radically different they are somewhat divergent. The scientist, seeking for a " shorthand" expression of a series, must proceed by selecting those features of things which they have in common, and by neglecting those which are individual. He empties out the peculiar features which to the clinical man are precious. To the scientist values are irrelevant, the clinical man thinks that it is only in being that one thing is better than another ; the scientist delights in the width of his comprehension of things, the clinical man tries to penetrate into the innermost recesses of the personality, and finds it to be no less inexhaustible. Moreover the practical man complains. that the scientist encourages the student to evade the discipline of particular diagnosis by instrumental short cuts. Happily however the majority of physicians are neither mere scientists nor mere clinicians, but partake of the qualities of both characters. The ideal therefore that we have to aim at is so to educate the student-graduate or undergraduate-that he shall not be a scientist detached from individual instances, but, whatsoever his calling. a practitioner ; a practitioner however whose clinical observation and invaluable traditional rules of thumb shall be enlarged and corrected by the breadth, the methods and the accuracy of analytic science. How is this end to be attained? To answer this question Sir George Newman and the Clinical Units are addressing themselves, and Dr. Wilson is examining their position and prospects.

\section{Composition of a CLINICAL UNIT.}

In any field of science and practice a small school must depend on the chances of individual leaders; but for the growth and advance of a large school the "spearhead" must be forged of more permanent and more various materials. The leader must not be superseded ; he must become the foreman of a team. Such a combination is called the "Unit"; and the members of it are in union to fortify, inspirit, and supplement each other in the search for and discovery of knowledge. This function, if less directly engaged in the teaching of students, yet makes for the life and increase of the whole school. In Medicine there has been, indeed, a great waste of workers. Young graduates of ability, attracted by the life and movement of the school, and unwilling to pass away at once into the somewhat superficial routine of practice, too often, during the most precious years of their lives, have been left to hover about the field while they ought to have been in the thick of the battle. These men are now to be welded into the spearhead, and will do brave work; helping on the cause, and training and storing their own minds before settling: down to more material engagements.

But who are to be the leaders? I am tempted to go so far as to say that, if possible, a school should not construct, or renew, its unit until it sees, within or without its own walls, the man it needs. It must have the foresight to discover its new leader among the young men, say under 40 years of age ; the leader should not be a mere clinician, nor merely a laboratory worker, but one who has a "footing in both camps," and knows the scope and power of each. He should produce evidence of work, not merely diligent and incidental, but systematic, consistent, coherent, and imaginative; work showing both grasp of detail and breadth of view ; and above all he must have in him the fire to kindle other men. These qualities should 
in this case be preferred to a gift of facile teaching ; if both cannot be had. The Unit may not teach much directly to the undergraduate, but it will form his teachers and "create an atmosphere." Those of us who had not such advantages - at any rate not at homefound out to our shame that on the old individual system it took us a quarter of a century to learn how to teach the beginner. And, as Dr. Wilson admirably says, in the Unit there is something more than the craft teaching-" nothing is so important (to the -students) as the mute example of the lives of their teachers, . . . that they should have in their midst a body of men whose lives are given to something other than the lucrative rewards of private practice."

And as for the Director, so for his associates; the settled work of the unit brings many blessings with it -not least a relief for a while from care and fuss, from hustling advertising methods, and anxious pressure towards premature publication. The organised worker has time to read and, what is better, to think, to assimilate new knowledge in meditation and converse, to sweeten his mind in familiarity also with art and letters; on the other hand, he has not to grudge the time for the prosecution of the more tedious and elaborate methods which make for thoroughness. If we fail to secure Directors having these ideals and qualities, the great expense of their institution will, as Dr. Wilson says, be wasted. Such a waste is to be deprecated at any time, at this time it is perilous to the whole movement. No risks must be run while parsimony is to begin, not in the fortresses of material ascendency, but upon the finer issues of the human spirit-in education, in health, in the finer arts, about which the public is supposed to be less vigilant.

\section{ELECTION OF Directors.}

The difficulty of securing Directors such as we desire suggests a few remarks on the mode of their election. It is easy now, when good appointments have been made in the London University, to say, nevertheless, that the mode leaves something to be desired. At present the election is virtually in the hands of the honorary staff of the hospital concerned. It is true that hitherto the hospital staffs have used their power loyally and with moderation; but this gives us no guarantee for the future. In the London University it would be better for the Senate to establish standing election committees, renewed by rotation, of independent-that is, ad hoc unofficialpersons of distinction in the several parts of Medicine. The hospital staff would thus be relieved of the duty not only to consider the claims of particular interests or promotions, but also those of past services or private friendships.

On the distribution of the teaching of the hospital I venture to formulate some definite principles. We are not to suppose that, in medicine, surgery, or gynæcology, to establish the Unit is to disestablish, or even to diminish, the teaching of the rest of the honorary staff. In my view of this matter the teaching of the undergraduate would remain almost wholly with the honorary and resident staff, as in the past; though the several parts and methods of it should be distributed and organised in some close dependance upon the Unit. Advanced instruction in the specialist departments would be in intimate association with the Unit. Do we not foresee two kinds or varieties of teaching; each to be distributed to its own quarters? The undergraduate knows that his time is short, and examinations near ahead; he wants his instruction to be precise, terse, and dogmatic; he is not ready for twilight apprehensions, nor for tentative and balanced judgments, nor for adventures on the outskirts of the known. $\mathrm{He}$ is apt to call them " rot." What he wants he will get better from the less speculative and more empirical side of the house. As I have said, our English teaching is for the prentice stage excellent, perhaps incomparable: do not let us disturb it. The director of the more advanced work, the team-work, will gather about him rather the pioneer squadron, the graduates who need "refresher" courses, men who have gained time and self-control enough to let loose a little imagination; he will attract the foreign visitors, and draw to his side-let us hope-some of his own honorary colleagues. Bence-Jones's frequent introduction of eminent foreign professors is among my happiest and most fruitful recollections of St. George's. Such an audience, such disciples, will be numerous enough to make the Directors' classes as large as they ought to be. And besides these there will always be borderers, half-ripe students moving between the junior and senior sides, who will blend the teaching into a whole, and diffuse the "creative atmosphere," the breath of the spirit on the face of the waters. If I may allude to my own experience, the Directors wil do wisely to make place incidentally for their brother directors of pathological and biochemical laboratories to address the classes on special or more knotty points of their several subjects. Thus the senion student is led to recall his half-forgotten drills and discarded text-books on physics and chemistry, to realise the unity of all these sciences, to discover in their search the omnipresence and omnipotence of surface actions, of ions, of catalysis, of colloid and other molecular chemistry, and so forth. Thus they learn also that to look forward they must continually look backward and beneath. Nevertheless each unit should be provided with its own small laboratory for current work; the larger or more continuous work being consigned to the central laboratories. Indeed the unit laboratory will be rather differently schemed and more specifically furnished. It can hardly be said as yet to exist in English hospitals, and abroad it is often too far from the wards. One general feature of the unit teaching however there must be which I would not overlook-one of wider appeal. The Director in each clinical department should be expected to give a clinical lecture-say once a week-in the chief theatre, generally with a patient before him; lectures which should be open free to all and any hearers, lay or medical (many biologists; \&c., are not doctors), who may choose to attend. Such lectures should be milestones on the pathways of hospital research, and, as they would need careful and leisurely preparation, one public lecture a week in term from each director is all that should be required. I would urge also that, if possible, a pupil of any one Unit should be made free of all Units, London and provincial.

The Out-Patient Departyent.

Now let me touch upon-I need do no more, as Dr. Wilson has made mention of it-a cardinal feature in the new system-namely, a radical reform of the Out-Patient Department. The changes needed, and the main lines of them, are, I think, so well recognised that I need not stay to dwell on them. But in view of these changes let us not, as Dr. Wilson warns us, overload the Directors with beds. The Director ought not to be burdened with routine, and the out-patient work, with its " beginnings of disease," will occupy much of his attention. One might suggest 40 beds, male and female, as sufficient if by the courtesy of his colleagues, he is offered some selection from the other beds in the house. By their aid he would be enabled to group cases along special lines of research. The intention is, I hope and believe, especially in the out-patient rooms, to invite outside practitioners to make use of the hospital for consultations in necessitous cases; and further perhaps, under some system of payments, for opportunities of hospital resources, such as $X$ ray work, cardiography, blood culture and morphology, metabolic rates, biochemistry, and so on for patients in less narrow circumstances. In these days of insurance, when almost everyone has his doctor, an office notice should be sent of every in-patient reception to the family practitioner, with a statement of the hours of attendance of the consulting staff and an invitation to attend if he wishes to do so. The wish would grow. We do not realise the waste and mischief of dismissing a patient after (say) eight weeks or more of elaborate investigation and treatment, often indeed 
of grave or crucial operation, and then leaving the home doctor in the dark to pick up the broken threads as he can. Moreover, with his aid the "following up" of patients will be made easier and more perpetual.

On the medical side I am strongly of opinion that insanities, at any rate in their manageable phases, should be included with other maladies in the ward and out-patient services, even if only for example's sake. The methods of convenience which exclude and segregate these diseases probably have a bad effect on the sufferers themselves, but they are infinitely more noxious in implanting and nursing the notion that "mental" disease is not bodily disease but something over, under, or beside it. What would be the misfortune to pathology if, let us say, diseases of the kidney were swept out of sight of general medicine? All bodily functions are interdependent; yet again, in tuberculosis, syphilis, and some other infections, such divorces are at least foreshadowed, and should be distrusted.

\section{Graduate Teaching.}

On the arrangements for graduate teaching I must make some brief remarks. Of the efforts made to this end by the Royal Society of Medicine and by individuals we cannot speak too gratefully. But, as in my correspondence with Sir William Osler, I drew back a little until the unit system should be settled and in action; for it seemed to me that the two movements must hang closely together. Before the Earl of Athlone's committee I demurred to, and indeed deprecated, the costly proposal of setting apart a peculiar hospital for this part of advanced instruction. Graduate teaching, if not confined to the units, must surely be sown, rooted, and watered in them. A central office and club for these graduates is desirable, but to separate their hospital study would cut the graduate off from the main streams of medical ideals, organisations, and activities; would deprive the units of their senior disciples, and compel the aspiring graduate, whose time is limited, either to desert the peculiar hospital or to surrender the privilege of attending the courses, and of coming under the influence, of one or more of the half a dozen most eminent leaders of the day in medicine and surgery, men of whose friendly encouragement he would have retained a happy memory for the rest of his days. As to the graduates who need only a " brush up," surely there are already in the great hospitals many competent teachers, and hundreds of beds, awaiting their arrival. If e are agreed that the choice of leaders is strait; these men are few, and these few are needed for the units; and as the senior men on the honorary staffs are not likely to desert their posts, so the staff of a hospital peculiar to graduates would fall into the second rank. But, after all, of the irony of the world we have many instances, and is there one more mordant than this that whatsoever we may do to develop and furnish the mind and enlarge the experience of the general practitioner, and to display to him what can be done, we send him away (unless he happens to practise near a university town) whither he will find none of these modern means for the application of his new knowledge. Is it not kinder to keep his eyes closed, and his mind in ignorance, that his soul may be at peace?

\section{Proportion in Medical Education.}

And these problems of education lead us on to other difficulties, which the units will have to work out. In his interesting and plain-spoken Hunterian Oration of $1921^{1}$ Sir Charters Symonds declares that in our zeal we are piling up the weight and number of subjects of medical instruction beyond all toleration. To lighten the burden Sir Charters Symonds proposes a utilitarian reform or rather retrogression; he advocates what, rightly or wrongly, is virtually a return to apprenticeship. The student is to be brought to the bedside at the outset, in order that he may have before

1 The Lancet, Feb. 19th, 1921. him continually the aptitudes for which he is to work. Anatomy is to be pruned, and a good third of it cut out, by rejections of its academic features (p. 12). Physiology is to be domesticated in like manner, but not so drastically. The peculiar discipline of anatomy as a standard of close observation and accuracy might thus be lost, for this discipline is all or nothing. Sir Charters Symonds (p. 15) "by no means wishes to be understood as decrying the study of the collateral sciences-these handmaids of medicine" (but) " do they hold, as taught to-day, their due proportion to the later subjects? However well informed a man may be in the preliminary sciences, the final court of appeal is at the bedside." He must attend rather to the cry of the children than to physical apparatus. And (p. 16) "The only opportunity the student has for independent observation, it seems to me, is in the clinical field, and the sooner he is brought there the better." (Italics in original.) 'This assertion seems a little hard on the present training in the "collateral " sciences. With one sentence at least we shall all hopefully agree-namely, that "one day we may see the physiologist at the bedside " (p.17). The pathologist should be a frequent, or indeed a regular, assessor.

Does not this discourse on the whole reflect the mind of the craftsman, and rightly so, but at the same tine diminish the scientific and thinking physician and surgeon? More than once I have discussed this sort of scheme with engineers, both professorial and practical, and find, with them as with ourselves, that promising as a plan of early shop work. may appear, the apparently irremediable consequence, in the ordinary student, is that at a later stage his attention to the science of his profession cannot be. recovered; he settles down on rule of thumb, and is quite contented without its principles. The houseniaid knows well enough how hot water may crack a glass vessel, but cares not why. But ere long the scope of the units will have to be reconsidered. I venture to repeat my oft-told opinion that the divorce of medicine and surgery, due to medieval disdain of handicrafts, cannot last. In this generation already it has landed us in an absurd position. Such specialism as must be will be on a plan, perhaps a topical plan, of redistribution, and the physician (to use the word in its general sense) must learn to deal, as does the gynæroloyist, with all sides of his case. And are not these phrases "collateral " sciences, " handmaids of medicine," and the like, misleading? These sciences are not annexes of medicine, nor frills about it, but partake of its very nature; they are mothers, not hirelings. As Sir David Prain said the other day to the Pharmacoutical Society: "Originally, practical pupilage worked tairly well. The surgical fabrace ... was patent to the eye, and (aseptic principles being unknown) success in practice depended on caution, manipulative skill, . . . natural capacity, and saving common-sense. But students discovered that they could not grasp (the underlying truths) ... without some kind of physics, and some understanding of the structure and function of vital mechanisms."

But it is true notwithstanding that the tides of teaching are overflowing the banks! What are we to do? We may indeed take parts of the past into the future, but we cannot walk backwards. At present we are asking what the Units will tell us. Sir Charters Symonds says that under the unit system the first year's men are being caller into the out-patient department; a call that should come from all the recognised teachers. He says also that no one desires to lengthen the curriculum. This may not be our desire but it is what we are inevitably doing. At Cambridge we are putting back the physics and chemistry to the schools, and with some success ; yet, even with this anticipation, university students are in their sixthseventh year when they come up for graduation. It may be that professional preparation will divide into two courses-into a five-years course on craft lines for the diploma of the colleges, and a university course for those who have the turn and the time for wider 
and deeper study ; a difference which is perhaps coming about, more or less undesignedly. In any case the universities must not trifle with their standards. At the Congress of Universities at Oxford, on July Sth, 1921, Prof. Joly dwelt on the educational value of even elementary research. He said: "I believe the outlook of a student who has carried out one single research of an elementary kind is different, from that of one $\bar{w}$ hose outlook is derived solely from the text-book and the examination. He learns first hand the mental point of view of the investigator. He gets ideas of scientific truth, and of the legion of errofs which lie in wait around it, as may in no other way be acquired. He sees the plausible prima facie conclusion break down under the control experiment, or in the light of the inexorable requirements of other participating laws of nature." This lesson we learn in Cambridge from our M.B. and M.D. theses; the student who has done no more than work up an M.B. thesis has awakened in himself a new faculty; he is a new man.

\section{Whole-Timee and Part-Time.}

One point of Dr. Wilson's article only remains: Is the director of a Unit to be a "whole-time man" or a " part-time man"? It may seem that with the growth of a reputation outside the hospital the temptation to strain a permission to accept outside calls would become irresistible. Again, it is said that the public have some claim on a physician or surgeon of exceptional skill ; and furthermore that some outside experience gives the professor a wider view of life, and makes for gentleness and humanity These last qualities surely have a rich soil for growth in the hospital itself. From my knowledge of foreign clinics, where the professoriate is generally on unit lines, I believe that usually some outside consultations are permitted; yet I am assured, on good authority in many cities, that no misunderstandings arise. The outside fees are pitched high, the professor has work enough to make him indisposed to add largely to it, and he oains moreover an affection for his clinic and a love for research which tend to keep him at home.

Finally however we shall abide by Dr. Wilson's counsel to go slowly, learning our way as we go; that we may develop a system, not in facile imitation of other countries and conditions, but in harmony with the needs and temperament of our own people.

PS. - The important memorandum presented to the University Grants Committee by Sir Wilmot Herringham and Sir Walter Fletcher on their return from the United States in May, 1921, came into my hands after this article had gone to press. All I can now do is to desire for it universal attention; and not in our profession only. It is an encouragement to find that the opinions and counsels of the authors are in close accord with my own.

\section{THE FIRST

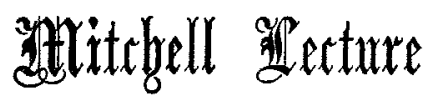

ON

\section{T U B E R C U L O I S :}

\section{ITS RELATIONS TO GENERAL BODILY CONDITIONS AND TO OTHER DISEASES.}

\section{Delivered on Nov. 1st, 1921, before the Royal College of Physicians, London,}

BY F. PARKES WEBER, M.A., M.D., F.R.C.P., PHYSICIAN TO THE GERMIN MOSPITAL, LONDON; FORJIERLY PHYSICIAN FOR CHEST DISEASES.

\section{Present Position of Tuberculosis Problem.}

MY lecture consists mainly in explanatory remarks on some of the main points of the modern tuberculosis problem, illustrated by the relations of the disease to other diseases and general conditions of the body.

The results of clinical observation and experimental research seem to show that tuberculosis, which Sir Robert Philip terms " a vicious by-product of an incomplete and ill-formed civilisation," is-if all "carriers" of tubercle bacilli and all cases of latent tuberculosis be included-so widely spread in the civilised communities of the world that it would be far more reasonable to try to segregate those individuals who have escaped infection than those who have been infected.1 On the other hand, amongst civilised communities the mortality from tuberculosis seems to be gradually diminishing, apparently as a result of: (1) Relative immunity to "massive" infection, due to infection during early life with minor forms of the disease; (2) diminished frequency of "massive" infection-a result of the modern application of hygienic preventive measures; (3) increase of the general standard of health-less poverty, less overcrowding, less overwork, better food, and better air.

In civilised communities infection (according to the results of von Pirquet's cuti-reaction and similar tests) chiefly takes place during childhood, the occurrence of congenital tuberculosis being so rare (see further on) that it is practically negligible. Apparently the initial infection generally escapes attention, and the disease is at once more or less effectually resisted by the natural vital processes of reaction in the body so that it remains permanently latent, the tubercle bacilli becoming quiescent or gradually dying out altogether. Obviously, all state or national antituberculosis schemes should include special attention to the welfare of children (especially the children of the poorer classes ) : (1) by furthering their general health: (2) by diminishing the chances of "massive" and frequently recurring infection-for example, by removing them (as is done by the French "Curre Grancher") from parents and others suffering from "open" tuberculosis; and (3) by methodically looking out for the first signs of infection and by employing the best means to oppose the disease directly that the first signs of infection are discovered. The tendency to suffer from severe or fatal tuberculosis probably varies somewhat according to inheritance (families and races) - that is to say, owing to a process of Darwinian survival of the fittest amongst communities which have been long exposed to tuberculous infection (Karl Pearson, \&c.). Doubtless, the chief reason why the disease especially often tends to assume a grave, rapidly progressive and fatal form in members of primitive communities is that they have hitherto escaped infection (owing to want of exposure) and in their resulting unprotected condition have, on their coming to live in towns or coming in contact with cases of open tuberculosis, been exposed to "massive" infection, just as unprotected children are exposed to " massive" and recurring infection by close contact with tuberculous parents, nurses, \&c. (suffering" from active and "open" tuberculasis).

\section{Routes of Entry of the Tubercle Bacillus.}

The most important routes by which tubercle bacilli gain admission to the body are by inhalation through the air-passages and by the alimentary canal. I may mention here that the placental route (congenital tuberculosis) is so rare that in 1916 I was able to collect practically all the known examples (published in various countries) into a short article on the subject. ${ }^{2}$ It is doubtful whether infection ever takes place from man to woman by the genital route. The bacilli very seldom enter the body by way of, or through, the skin, but infection by this route has probably occasionally occurred, for instance, in connexion with the operation of circumcision, by chance wounds, or by direct cutaneous inoculation in various ways. In patients with lupus vulgaris or " scrofulodermatous" lesions, who likewise suffer from tuberculosis of the lungs or other internal parts, the infection with tubercle bacilli has almost certainly been much more often carried from the internal parts to the skin than from the skin to the internal parts. 